УдК 330.322 .1

\title{
B.С. Шибаев
}

Владивостокский государственный университет экономики и сервиса Владивосток. Россия

\section{Когнитивная экономика и коэффициент интеллекта: зарубежный взгляд}

В статье анализируются исследования, посвященные влиянию макропсихологических параметров (например, средний коэффициент интеллекта) на экономический потенциал и развитие экономики государства. В статье представлены основные зарубежные исследования по выбранной тематике (поскольку это направление наиболее распространено в настоящий момент в англоязычных странах, в частности в США), их критика, включающая статистическую проверку и её интерпретацию. Представленные данные свидетельствуют о том, что именно такая психологическая переменная, как средний коэффициент интеллекта (на индивидуальном и групповом уровнях), станет модерирующей и прогностической по отношению к ВВП и другим экономическим показателям.

Ключевые слова и словосочетания: когнитивные способности, интеллект, IQ, BBП, экономическое развитие, когнитивная экономика, когнитивный капитализм.

\section{V.S. Shibaev}

Vladivostok State University of Economics and Service Vladivostok. Russia

\section{Cognitive economics and IQ: a foreign view}

This article analyzes studies on how such macropsychological parameters as the average IQ can affect the economic potential and development of the state's economy. The article gives an overview of both the main foreign large works on this topic (since these studies are most common at the moment in the Anglosphere, in particular, in the USA), their criticism, including statistical verification and its interpretation. The data presented in this analysis speaks in favor of the fact that it is such a psychological variable as the average IQ (both at the individual and at the group level) can moderate and predict GDP and other economic indicators.

Шибаев Владимир Сергеевич - ассистент кафедры философии и юридической психологии; e-mail: wladimirdw@gmail.com 146 
Keywords: cognitive abilities, intelligence, IQ, GDP, economic development, cognitive economics, cognitive capitalism.

\section{Введение}

Вопрос о том, почему одни народы богаты, а другие - нет, волнует человечество многие столетия, если не сказать тысячелетия. Долгое время он находился в ведении исключительно экономической науки. Однако с ростом междисциплинарности исследовательских практик и сближением предметной области исследования отдельных ответвлений психологической и экономической наук на этот актуальный вопрос в современной России пытаются ответить исследователи, занимающиеся макропсихологическими проблемами. Прежде всего, необходимо кратко охарактеризовать современные теории экономического неравенства.

В статье Хайнера Риндерманна «Интеллектуальные классы, технологический прогресс и экономическое развитие: расцвет когнитивного капитализма» [12] предложена схема постепенного усиления когнитивных способностей, приведших к увеличению достатка населения, что, в свою очередь, улучшило среду их обитания (которая также оказывает определенное влияние на когнитивные способности, что снова увеличило материальный достаток населения и т.д.). Риндерманн анализирует теории, которые пытаются объяснить мировое экономическое неравенство, замечая, что феномен богатства одних и бедности других волновал людей с давних пор. Ученый разделяет эти подходы следующим образом:

1. «Либертарианский подход» («libertarian approach») - утверждается, что наиболее развитыми в экономическом отношении, а, следовательно, и наиболее богатыми государства стали благодаря наличию в них наибольшей степени экономической свободы. Действительно, согласно Риндерманну, существует корреляция между экономической свободой и благосостоянием государства. Однако расцвет восточно-азиатских экономик с большой долей государственного влияния противоречит либертарианской теории.

2. Теории «культурной ориентированности» («cultural orientations») - основой экономического неравенства является господствующая культурно-религиозная традиция - будь то конфуцианство, протестантизм или иудаизм. Так, например, Макс Вебер указывал на бюргерскую культуру и Просвещение как на источники зарождения и развития капитализма. Однако теории культурной ориентированности никогда не проходили адекватную статистическую проверку.

3. «Теории зависимости» («dependency theories») - определяют экономическое развитие наций как результат неравномерности развития производящих сил. Эти теории берут за основу идеи Карла Маркса, но не способны объяснить большие различия в экономическом развитии развивающихся стран, например, различие в экономике Ганы и Южной Кореи. Многие страны испытывали серьезный экономический спад в период деколонизации, однако последующий рост был прочно связан с успешностью копирования передовых технологий развитых стран.

4. Географические теории - объясняют различие в экономике наличием или отсутствием у государств необходимых ресурсов или других преимуществ для 
развития (благоприятный климат, возможность внутриконтинентального обмена ресурсами, количество возможных для одомашнивания видов и т.д.). Разумеется, подчеркивает Риндерманн, такие преимущества могут увеличить благосостояние страны, однако наличие ресурсов может привести не только к росту благосостояния, но и к его потере (например, после беспощадной эксплуатации имеющихся ресурсов). Также эти теории не объясняют высокого экономического роста стран, имеющих явные географические и ресурсные недостатки (Швейцария, Сингапур, Тайвань или Новая Зеландия)

После краткой характеристики современных теорий экономического неравенства перейдем к обзору основных работ, посвященных «когнитивноэкономической» теории.

\section{Основная часть}

Работы в рамках этой теории стали активно появляться в начале XXI века: в них исследовались связи национального IQ с экономическим состоянием и ростом $[2-7 ; 11 ; 15 ; 17 ; 18 ;]$. Целесообразно подробно остановиться на фундаментальной работе «Интеллект: единый конструкт для социальных исследований», которая одной из первых представила объемный анализ взаимосвязи среднего коэффициента интеллекта в стране с её экономикой [9]. Анализ был расширен до 199 стран, а количество переменных до 61, разделенных по тематическому принципу. В исследование были включены корреляции между IQ и образовательными достижениями, экономикой, политическими институтами, уровнем здравоохранения, уровнем рождаемости, уровнем санитарии, уровнем преступности, религиозности, счастья и индексом жизненных условий (Index of Human Conditions). Что касается экономической составляющей данного анализа, то наиболее интересующая нас корреляция Спирмена между ВВП 2008 года и IQ составила 0,709 для 197 стран, что в целом соответствует значениям [9].

Нельзя сказать, что развитие данных идей принимается благожелательно ввиду как идейно-политических мотивов [10], так и научной критики. В статье Д. Вэтцель и М. МакДэниэла [17] суммирована критика, относящаяся к «IQ и благосостоянию наций»: сомнения в репрезентативности выборок, в эквивалентности средств измерения (тесты, сконструированные в одной культуре, могут «не работать» в другой). Особенно сильные сомнения подобного рода выражались в отношении измерений в странах, находящихся на нижнем конце распределения средних значений IQ. Кроме того, критиковалась данная Линном и Ванханненом (авторами труда) каузальная интерпретация связи между IQ и экономическим развитием.

Авторы статьи провели свой собственный анализ, результаты которого позволили им утверждать, что наиболее эффективно экономическое процветание страны предсказывается по национальному IQ (в случае, когда его оценки ниже 90 приравнены к этому значению), уровню экономической свободы в стране и расходам на здравоохранение на душу населения. Вместе эти три предиктора объясняют около 90\% дисперсии экономического процветания [16]. Следует остановиться на данной работе более подробно ввиду того, что авторы подвергли проверке устойчивость сообщенных Линном и Ванханненом связей при исполь- 
зовании других данных (обновленных оценок национального IQ, BBП на душу населения за другой год и пр.), а также рассмотрели характер связи национального IQ с BBП на душу населения. Исследователи Вэтцель и МакДэниэл пришли к следующим результатам:

1) используя линейную модель, Линн и Ванханнен получили корреляцию в 0,62 между национальным IQ и BBП на душу населения в 1998 году. Вэтцель и МакДэниэл, используя обновленные оценки IQ и ВBП на душу населения, в 2002 году получили корреляцию в 0,60. Аналогичным образом были повторены и результаты Линна и Ванханнена, продемонстрировавшие увеличение предсказательной силы модели при включении в нее в качестве предикторов показателей демократизации и экономической свободы, используя другие меры для этих переменных (множественная корреляция у Линна и Ванханнена составляла 0,79, у Вэтцель и МакДэниэла - 0,80). Таким образом, результаты Линна и Ванханнена являются устойчивыми к изменению источников данных;

2) Вэтцель и МакДэниэл обнаружили, независимо от Дикерсона [17], что взаимосвязь IQ и BBП становится гораздо выше, если использовать нелинейную модель. При введении в модель квадрата оценки IQ эффективность предсказания заметно возрастала и когда предсказывался ВВП на душу населения в 1998 г. (множественная корреляция возрастала с 0,62 до 0,67), и когда предсказывался ВВП на душу населения в 2002 г. (множественная корреляция возрастала с 0,61 до 0,67) [17];

3 в в ответ на критические возражения в адрес работы Линна и Ванханнена некоторых авторов, сомневающихся в верности оценок национального IQ, особенно в нижней части распределения, Вэтцель и МакДэниэл приравняли оценки всех стран, у которых они были ниже 90, к 90. Несмотря на сужение интервала оценок, коэффициенты корреляции с ВВП на душу населения в 1998 и 2002 г. несколько возросли. Таким образом, возможные неточности низких оценок национального IQ не представляют угрозы для положения Линна и Ванханнена о влиянии национального IQ на экономическое благосостояние;

4) экономическая свобода, демократия и производство нефти на душу населения вносят независимый вклад в предсказание национального благосостояния при использовании их как дополнительных к национальному IQ предикторов;

5) такой показатель, как расходы на образование одного учащегося, используемый как дополнительный к национальному IQ предиктор национального благосостояния, не увеличивает предсказательной силы модели, несмотря на то, что существует корреляция между данным показателем и ВВП на душу населения в 0,21 ;

6) в отличие от предыдущего показателя затраты на общественное здравоохранение как дополнительный к IQ предиктор существенно увеличивают предсказательную силу модели. Таким образом, национальный IQ совместно с затратами на здравоохранение объясняет 86\% вариации благосостояния стран [17];

7) наиболее высокой предсказательной силой как предикторы ВВП на душу населения страны обладают национальный IQ (при приравнивании его значений ниже 90 к 90), уровень экономической свободы, а также уровень расходов на здравоохранение. Множественная корреляция этих трех показателей с ВВП на душу населения равна 0,95, что объясняет 90\% вариации ВВП между странами. 
Вэтцель и МакДэниэл касаются вопроса о направлении связи IQ-BВП. Они отмечают, что Линн и Ванханнен подверглись критике за каузальную интерпретацию этой связи, поскольку утверждали, что IQ детерминирует ВBП, приводя в качестве аргумента тот факт, что IQ является в значительной степени наследуемым признаком. Это утверждение, согласно Вэтцелю и МакДэниэлу, принимается не всеми. Далее ученые объясняют, что проведенный ими самими анализ мало дает для разрешения вопроса о направлении связей между национальным благосостоянием и переменными, которые рассматривались как предикторы.

Анализ, проведенный Вэтцелем и МакДэниэлом, подтвержден надежностью данных, использованных авторами «Глобального неравенства», а также их положением о связи между IQ, ВВП и другими переменными. Таким образом, можно подытожить, что взаимосвязь между средним интеллектом населения страны и национальным благосостоянием является достаточно тесной.

Кроме того, влияние IQ на BBП, как показано в исследовании Джоунса и Шнайдера «Intelligence, Human Capital, and Economic Growth: A Bayesian Averaging of Classical Estimates (BACE) Approach», не объясняется действием третьих переменных [8]. Авторами были построены 18 регрессий с 54 наблюдениями IQ, в которых переменные варьировались от ожидаемой продолжительности жизни до фактора колониальной истории страны. Авторы работы включили все возможные комбинации трёх переменных с 21 фактором экономического роста страны, выделенных экономистом X. Сала-и-Мартином. Результат показал, что модели, в которые был включен IQ как фактор роста национального ВВП, лучше предсказывали рост экономики, нежели те, где IQ как фактор был исключен (IQ имел апостериорную вероятность в 96,6\%) [8]. В дополнение фактор IQ показал значимость на уровне $0,1 \%$ в $92 \%$ регрессий и $0,0001 \%$ уровень значимости в $61,43 \%$ регрессий. Кроме того, влияние IQ на экономику должно быть выше в странах, в которых имеется соревновательная рыночная экономика - более высокие зарплаты выплачиваются тому, кто может произвести более высокий предельный продукт труда. В свою очередь, работники, способные производить такой продукт, обладают более высоким IQ. Джоунс также продемонстрировал, что в зависимости от значения, выбранного для доли капитала, влияние IQ на предельный продукт труда варьируется от 26 до 56\% объясненной дисперсии в межстрановом анализе [7]. Кроме того, авторы исследования обнаружили, что рост национального IQ на 1 балл даёт рост устойчивого ВВП от 1,5 до 4\% на работника; рост IQ на 1 балл повышает уровень жизни приблизительно на 6,1\% [8].

В статье Э. Ханта и В. Виттмана «National intelligence and national prosperity» осуществляется проверка, сохраняет ли силу связь IQ с экономическим благосостоянием на множестве развивающихся стран [6]. Такая проверка была вызвана критикой, высказываемой в адрес использования тестов интеллекта вне культуры, в которой они были созданы, поскольку в другой культуре тесты не могут считаться валидными. Авторы рассчитали корреляцию национального IQ с показателем благосостояния отдельно для подмножеств развитых и развивающихся стран. Полученные значения составили 0,58 и 0,70 соответственно, что, конечно же, не поддерживает критику использования тестов в развивающихся странах. Тем не менее, отмечают авторы, ошибка предсказания в среднем происходит чаще 
в случае развивающихся стран. Исследователи склонны оставить в силе сомнение в валидности тестов интеллекта вне рамок индустриального и постиндустриального мира. В целом же при их явно критической установке авторы считают, что полученные данные подтверждают заключение Линна и Ванханнена о связи мер «когнитивной компетентности» населения страны с состоянием ее экономики.

Касаясь направления связи интеллекта и благосостояния наций, Хант и Виттман указывают на лонгитюдинальные исследования. Отметив трудности, с которыми сталкиваются перечисленные подходы, Риндерманн переходит к теории Линна и Ванханнена, утверждающей, что когнитивный уровень нации является главным детерминантом ее благосостояния. Он делает попытку разрешить вопрос о направлении связи интеллекта и благосостояния наций. В более ранней работе Риндерманн уже отмечал, что срезовые исследования, которыми обычно являются исследования связи интеллекта и благосостояния, не могут дать указания на направление связи между национальным IQ и уровнем национального благосостояния [13]. Действительно, даже если срез по интеллекту предшествует срезу по благосостоянию, нельзя исключить направления связи от благосостояния к интеллекту: благосостояние в прошлом может соответствовать более позднему срезу и определять уровень интеллекта на тот момент, создавая связь более ранних измерений интеллекта с более поздними данными о благосостоянии. Более информативным относительно направления связи IQ и уровня благосостояния наций, утверждает Риндерманн, будет лонгитюдинальное исследование, когда и показатели интеллекта, и показатели благосостояния (a, возможно, и дополнительные показатели) берутся за разные моменты времени и рассматриваются стандартизированные путевые коэффициенты ( $\beta$ ) между ними (не корреляции). Так, в двух таких анализах, представленных в более поздней работе Риндерманна [13], взяты следующие показатели: в первом анализе - среднее количество лет, потраченных на обучение в школе за 1970 и 2000 гг.; уровень экономической свободы в 1970 и 2000 гг.; логарифм ВВП по паритету покупательной способности на душу населения за 1970 и 2000 гг.; во втором анализе - показатель когнитивной компетентности в 1964-1972 гг. и в 1995-2007 гг.; уровень экономической свободы в 1970 и 2000 гг.; логарифм ВВП по паритету покупательной способности на душу населения за 1970 и 2000 гг.

Объединенные результаты этих анализов и анализов, представленных в более ранней работе [13], показали следующее:

1) когнитивная компетентность важнее для уровня благосостояния $(\beta=0,33)$, чем наоборот $(\beta=0,11)$;

2) более важна когнитивная компетентность $(\beta=0,33)$ для роста благосостояния , нежели уровень экономической свободы $(\beta=0,12)$;

3) когнитивная компетентность положительно влияет на рост экономической свободы в государстве ( $\beta=0,39$ vs. благосостояние на экономическую свободу: $\beta=0,33$ vs. экономическая свобода на когнитивную компетентность: $\beta=0,15)$. 
Таким образом, существует обоюдный эффект между ВВП и когнитивными способностями населения $(\beta=0,33$ и $\beta=0,11)$, но при этом эффект интеллекта сильнее [12].

\section{Выводы}

Положение о зависимости экономического благосостояния от IQ подтверждают и другие данные:

1. Исследования, сравнивающие социально-экономический успех (SES) индивидов c IQ и социально-экономическим статусом их родителей. Связь личного социоэкономического успеха с индивидуальным IQ выше $(\mathrm{r}=0,21)$, чем с социально-экономическим статусом родителей индивида $(\mathrm{r}=0,16)$ [14]. Таким образом, индивид, создающий среду вокруг себя, становится действующим актором «когнитивного капитализма», описанного Риндерманном.

2. Исследования индивидуального и группового уровней IQ, показывающие большую склонность людей с высоким IQ больше сохранять деньги, а также их большую терпеливость. В то же время страны с более высоким национальным IQ имеют более высокий доход. Существует корреляция между долговременным экономическим поведением и национальным IQ, что говорит о том, что индивидуальное экономическое поведение влияет на экономический рост государства в целом [5].

3. Исследования, демонстрирующие связь между распределением таланта и экономическим развитием государства. Наблюдается устойчивая корреляция между сложностью работы и уровнем IQ, а также талантливостью. Помимо этого, проанализирована взаимосвязь между отбором наемных работников компанией и ВВП, получены данные о том, что те компании, которые нанимают на свои должности сотрудников, проходящих тесты на когнитивные способности, имеют более высокий доход и более высокие продажи [16]. Кроме того, существуют данные о распределении таланта на уровне не только стран, но и, например, на уровне штатов США [1]. Таким образом, положительная взаимосвязь между талантливостью и сложностью работы, наличие которой повышает экономическое развитие государства, подтверждает изложенную выше теорию [15].

4. Исследования, устанавливающие связь между IQ и благосостоянием. Доказано, что национальный IQ выступает важным предиктором для роста благосостояния. В исследовании Хафера фактор IQ был наиболее объясняющим $(0,649)$ ВВП, чем остальные использованные им переменные [4]. Эти данные служат важным показателем того, что IQ является хорошим экономическим предиктором и управляющим элементом в связке с экономикой, а не наоборот.

1. Allik J., Realo A. Individualism - collectivism and social capital // Journal of CrossCultural Psychology. - 2004. - №35. - P. 29-49.

2. Barber N. Educational and ecological correlates of IQ: a cross-national investigation // Intelligence. - 2005. - Vol. 33. - P. 273-284.

3. Dickerson R. Exponential correlation of IQ and the wealth of nations // Intelligence. 2006. - Vol. 34. - P. 291-295.

4. Hafer R. New estimates on the relationship between IQ, economic growth and welfare // Intelligence. - 2017. - Vol. 61. - P. 92-101.

152 
5. Hafer R.W. Cross-country evidence on the link between IQ and financial development // Intelligence. - 2016. - Vol. 55. - P. 7-13.

6. Hunt E., Wittman W. National intelligence and national prosperity // Intelligence.2008. - Vol. 36. - P. 1-9.

7. Jones G. IQ in the Ramsey Model: A Naïve Calibration // SSRN Electronic Journal. 2005. - № 213. - URL: https://ssrn.com/abstract=755584 (дата обращения: 12.11.2020).

8. Jones G., Schneider W. Intelligence, Human Capital, and Economic Growth: A Bayesian Averaging of Classical Estimates (BACE) Approach // Journal of Economic Growth. 2006. - Vol. 11, Is. 1. - P. 71-93.

9. Lynn R., Vanhannen T. Intelligence: an unifying construct for social sciences. - London: Ulster Institute for Social Research, 2012. - 530 p.

10. Nyborg H. The sociology of psychometric and bio-behavioral sciences // The scientific study of general intelligence. - Oxford: Pergamon, 2003. - P. 441-502.

11. Ram R. IQ and economic growth: Further augmentation of Mankiw-Romer-Weil model // Economics Letters. - 2007. - Vol. 94. - P. 7-11.

12. Rindermann H. Intellectual classes, technological progress and economic development: the rise of cognitive capitalism // Race and sex differences in intelligence and personality. A tribute to Richard Lynn at 80 / ed. by H. Nyborg. - London: Ulster institute for social researches, 2013. - P. 131-168.

13. Rindermann $\mathrm{H}$. Relevance of education and intelligence at the national level for the economic welfare of people // Intelligence. - 2008. - Vol. 36, Is. 2. - P. 127-142.

14. Strenze T. Intelligence and socioeconomic success: A meta-analytic review of longitudinal research // Intelligence. - 2007. - Vol. 35. - P. 401-426.

15. Tarmo S. Allocation of talent in society and its effect on economic development // Intelligence. - 2013. - Vol. 41. - P. 193-202.

16. Terpstra D. E., Rozell E. J. The relationship of staffing practices toorganizational level measures of performance // Personnel Psychology. - 1993. - №46. - P. 27-48.

17. Whetzel D. L., McDaniel M. Prediction of national wealth // Intelligence. - 2006. Vol. 34. - P. 449-458.

18. Zajenkowski M., Stolarski M., Meisenberg G. Openness, economic freedom and democracy moderate the relationship between national intelligence and GDP // Personality and Individual Differences. - 2013. - №55. - P. 391-398.

(ㄱ В.С. Шибаев, 2020

Для цитирования: Шибаев В. С. Когнитивная экономика и коэффициент интеллекта: зарубежный взгляд // Территория новых возможностей. Вестник Владивостокского государственного университета экономики и сервиса. - 2020. - Т. 12, № 4. - С. 146-153.

For citation: Shibaev V. S. Cognitive economics and IQ: a foreign view, The Territory of New Opportunities. The Herald of Vladivostok State University of Economics and Service, 2020, Vol. 12, № 4, pp. 146-153.

DOI dx.doi.org/10.24866/VVSU/2073-3984/2020-4/146-153

Дата поступления: 30.11.2020. 